\title{
Prehospital Cross-Sectional Study of Drowning Patients Across the United States
}

\author{
Lucas M. Popp, BA, EMT-P; Nicklaus P. Ashburn, MD; Henderson D. McGinnis, MD; Jason P. Stopyra, MD, MS \\ Department of Emergency Medicine, Wake Forest School of Medicine, Winston-Salem, North Carolina
}

Introduction-Every year drowning is responsible for $7 \%$ of injury-related deaths worldwide, making it the third leading cause of unintentional injury-related death. However, in the United States, little is known regarding the prehospital presentation and management of these patients. The purpose of this study was to describe the drowning population in the United States, with a focus on prehospital time intervals, transport, and cardiac arrest frequency.

Methods-A retrospective cross-sectional study was performed querying records from emergency medical services encounters across the United States over 30 mo (January 2016 to July 2018) using the ESO (Austin, TX) national emergency medical services data registry. Patients with a dispatch or chief complaint of drowning were included. Descriptive statistics, binomial proportion tests, and general linear and logistic regression models were used.

Results-There were 1859 encounters that met the study criteria. Median age was 18 y ( $\mathrm{n}=1855$, LQUQ 4-46). Pediatric patients accounted for 50\% $(n=919,95 \%$ CI 47-52). Cardiac arrest occurred in $29 \%(\mathrm{n}=537,95 \%$ CI $27-31)$, and return of spontaneous circulation occurred in $37 \%(\mathrm{n}=186,95 \%$ CI 32-41). Times were $8 \pm 5,19 \pm 17$, and $15 \pm 10 \mathrm{~min}($ mean \pm SD) for arrival, on-scene, and transport times, respectively.

Conclusions-This national prehospital drowning study demonstrated that despite an $18 \%$ fatality rate in drowning encounters, patients were more likely to have return of spontaneous circulation when compared to the overall prehospital national average, with rates higher in pediatric patients. Future studies with outcomes data should focus on identifying factors that improve cardiopulmonary resuscitation success rates.

Keywords: emergency medical services, pediatric, cardiac arrest, return of spontaneous circulation

\section{Introduction}

Drowning is responsible for approximately $7 \%$ of all injury-related deaths worldwide each year according to the World Health Organization, making it the third leading cause of unintentional injury-related death. In the United States, drowning is the second leading cause of injury-related death among children 1 to 4 y of age. ${ }^{1}$ The

Preliminary data were presented at the Society of Academic Emergency Medicine's southeast regional meeting in 2020 in Greenville, North Carolina, and national meeting in 2020 in Denver, Colorado.

Corresponding author: Lucas M. Popp, BA, EMT-P, Wake Forest School of Medicine, 1 Medical Center Boulevard, Winston-Salem, NC 27157; e-mail: 1popp@wakehealth.edu.

Submitted for publication September 2020.

Accepted for publication March 2021.
Centers for Disease Control report that 1 in 5 people who die from drowning are children aged $14 \mathrm{y}$ and younger, with many additional pediatric patients requiring treatment and hospitalization for nonfatal submersion injuries. For every fatal drowning reported, it is estimated that another 5 persons seek emergency care for nonfatal drownings. ${ }^{2}$ This could indicate a severe underreporting and misrepresentation of the burden of drowning.

Drowning is a sudden or progressive respiratory impairment from submersion or immersion in liquid. Aspiration impairs oxygen exchange, which results in hypoxia. ${ }^{4}$ Hypoxia leads to cardiac rhythm abnormalities, typically tachycardia followed by bradycardia, pulseless electrical activity, and, ultimately, asystole. ${ }^{4-6}$ The whole drowning process, from submersion to cardiac arrest, typically occurs in seconds to minutes. ${ }^{7}$ Exceptions can 
prolong this process, particularly with extremes in environmental temperature. ${ }^{7}$ Because of the rapid deterioration in drowning patients, early response and recognition by prehospital care providers is imperative for positive outcomes.

Emergency medical services (EMS) play an important role in patient outcomes, but a critical evidence gap exists regarding the prehospital presentation and management of drowning patients. Patients present with logistic and environmental challenges not seen in typical prehospital encounters, and an understanding of patient presentation and time intervals is imperative in developing treatment and risk reduction protocols for this population. The purpose of this study was to describe drowning patients in the United States, with a focus on prehospital time intervals, transport, and cardiac arrest frequency.

\section{Methods}

A national retrospective cross-sectional study of drowning patients from across the United States was performed by querying patient care reports from 1314 EMS agencies collected over 30 mo (January 2016 to July 2018) using a de-identified research database maintained by ESO, Inc. (Austin, TX). All agencies that use the ESO system were included. Prehospital providers manually enter data into the ESO electronic health record (EHR) to approximate the care they provide for each patient. Records with a dispatch or chief complaint of "drowning" were included in the study. The ESO prehospital EHR software facilitates the collection of comprehensive clinical information, including event dispatch data, patient demographic characteristics, clinical presentation and course, interventions and treatments, and outcome at the transfer of care. Data elements collected within the ESO database are compliant with the National EMS Information System standard, which increases the standardization of collected data across EMS systems. Data fidelity was ensured by direct population of the ESO research database from the ESO EHR. The institutional review board at Wake Forest University Health Sciences approved this investigation and waived the requirement for informed consent. The strengthening the reporting of observational studies in epidemiology guidelines helped direct the research and article development processes. ${ }^{8}$

All EMS encounters with a dispatch or chief complaint or impression of "drowning" were included in the analysis. Patients were excluded if they were declared dead in the field with no resuscitation attempted. Interfacility transport patients were not included. Patients were categorized by age, sex, race, and transport
Table 1. Defined variables with ESO category chosen by prehospital provider

\begin{tabular}{|c|c|}
\hline Variable & ESO category \\
\hline \multirow{6}{*}{$\begin{array}{l}\text { Level of service } \\
\text { Basic life support } \\
\text { Advanced life } \\
\text { support }\end{array}$} & Level of service \\
\hline & Basic life support \\
\hline & Advanced life support \\
\hline & Advanced life support 2 \\
\hline & Basic life support, upgraded \\
\hline & Critical care \\
\hline $\begin{array}{l}\text { Transport decision, } \\
\text { urgency }\end{array}$ & Disposition \\
\hline \multirow{5}{*}{$\begin{array}{l}\text { Transported, } \\
\text { emergent } \\
\text { Transported, } \\
\text { nonemergent }\end{array}$} & Transported lights/siren \\
\hline & Transported no lights/siren upgraded \\
\hline & Transported no lights/siren \\
\hline & $\begin{array}{l}\text { Patient treated, transferred care to } \\
\text { another EMS professional }\end{array}$ \\
\hline & $\begin{array}{l}\text { Patient dead on scene, resuscitation } \\
\text { attempted (with transport) }\end{array}$ \\
\hline \multirow[t]{8}{*}{ Not transported } & Assist \\
\hline & Dead on scene \\
\hline & No treatment, no transport \\
\hline & Patient care transferred \\
\hline & Patient treated, no transport \\
\hline & Personnel aiding in transport \\
\hline & Treated, transported by private vehicle \\
\hline & Treatment, no transport \\
\hline \multirow{2}{*}{$\begin{array}{l}\text { Cardiac arrest } \\
\text { Cardiac arrest }\end{array}$} & Cardiac arrest \\
\hline & $\begin{array}{l}\text { Yes, after EMS arrival } \\
\text { Yes, before EMS arrival }\end{array}$ \\
\hline No cardiac arrest & No \\
\hline \multirow{7}{*}{$\begin{array}{l}\text { Return of } \\
\text { spontaneous } \\
\text { circulation } \\
\text { ROSC }\end{array}$} & ROSC occurred \\
\hline & After ALS \\
\hline & After bystander CPR only \\
\hline & After bystander defibrillation shock \\
\hline & After EMS CPR only \\
\hline & After EMS defibrillation shock \\
\hline & $\begin{array}{l}\text { Return of spontaneous circulation (in } \\
\text { discontinuation reason) }\end{array}$ \\
\hline \multirow[t]{2}{*}{ No ROSC } & Never \\
\hline & Unknown \\
\hline
\end{tabular}

ALS, advanced life support; CPR, cardiopulmonary resuscitation; EMS, emergency medical services; ROSC, return of spontaneous circulation.

decision. Age was categorized as adult or pediatric, with pediatric defined as $<18$ y old. Race was categorized into White, African American, Latino, and Other. Race categories were determined by predefined ESO user input options.

Patient data were categorized based on inputs into the EHR system, defined in Table 1. Prehospital times included response time, on-scene time, and transport time. These were defined as the difference between dispatch time and arrival time, arrival time and scene 

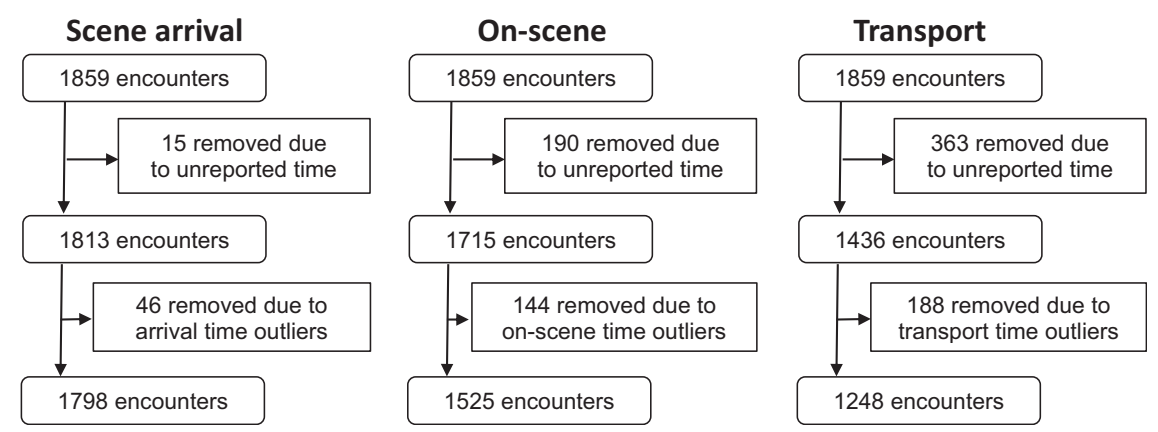

Figure 1. Case selection flow diagram for prehospital time intervals.

departure time, and scene departure time and destination arrival time, respectively. Only those transported were included in the transport interval analysis. Advanced life support was defined as services provided exceeding the capabilities of a basic emergency medical technician. Cardiac arrest and return of spontaneous circulation (ROSC) occurrence were assessed by the prehospital provider as the absence or return of a pulse.

Descriptive statistics were used to characterize the sample. Age was presented as median and interquartile range. Mean times were presented with SD. Encounters were excluded from the time interval calculations if there was an unreported value for the specified time interval. Zero-minute and negative time intervals were also excluded. Certain events, such as failure to regain ROSC after cardiac arrest, produced scenarios with time intervals that did not represent the typical prehospital drowning patient encounter and were thus excluded. Extreme rightward limits were defined as time values greater than $3 \mathrm{SD}$ above the mean, resulting in upper limits of 25,115 , and $53 \mathrm{~min}$ for response time, on-scene, and transport intervals, respectively (Figure 1). Values exceeding these limits suggest failed or withheld resuscitation attempts or improper data entry, none of which accurately represent time standards of a patient transported by EMS, and were thus excluded.

Binomial proportion tests were used to determine the significance of the categorical variables when compared to the theoretically expected value. General linear models were used to compare the effects of age, sex, race, and cardiac arrest on EMS time intervals. A logistic regression with odds ratios (ORs) was used to compare the same predictors for cardiac arrest and ROSC occurrence. Age was treated as a categorical variable owing to the effect age-based EMS protocols could have on the linear and logistic models. Statistical significance was determined with $95 \%$ CIs of measured proportions between categories with an a priori alpha level of 0.05 . Post hoc analysis of 1859 encounters revealed that the statistical power for this study exceeded 0.99 for measuring effect size. Values compared with previous studies were deemed significant with comparison to the confidence interval for difference between proportions (CIDP). SAS 9.4 (SAS Institute Inc., Cary, NC) was used to conduct statistical analyses.

\section{Results}

There were 1859 drowning encounters (Table 2). Binomial proportion tests are reported in Table 3 . The median age was 18 y ( $\mathrm{n}=1855$, LQ-UQ 4-46). Pediatric encounters accounted for $50 \%(\mathrm{n}=919,95 \%$ CI 47-52) of the sample. Males accounted for $65 \%(n=1200,95 \%$ CI 63-67) of the sample, and white patients accounted for $69 \%(n=1231,95 \%$ CI 67-72).

Overall response time was $8 \pm 5 \mathrm{~min}$. Overall on-scene time was $19 \pm 17 \mathrm{~min}$. Overall transport time was $15 \pm 10$ min. A general linear model for EMS response times that accounts for age, sex, race, and cardiac arrest presentation is presented in Table 4. On-scene time was shorter for younger patients $(\beta=-0.9,95 \% \mathrm{CI}-10.4$ to -7.9$)$ and longer for cardiac arrest patients $(\beta=3.4,95 \%$ CI 2.1-4.8); transport time was shorter for African American patients ( $\beta=-2.6,95 \% \mathrm{CI}-4.0$ to -1.2$)$ and cardiac arrest patients ( $\beta=-3.4,95 \% \mathrm{CI}-4.7$ to -2.2 ). Associations between pediatric cardiac arrests and time intervals were nonsignificant.

Advanced life support treatment was provided to $79 \%$ $(\mathrm{n}=874,95 \%$ CI $64-70)$ of the sample. Encounters transported by EMS accounted for $67 \%(n=1248,95 \%$ CI 65-69) of the sample, with the remaining encounters providing alternative means of hospital transport or refusing medical treatment. Of those encounters transported, $62 \%(\mathrm{n}=774,95 \%$ CI 59-65) were transported as 
Table 2. Descriptive statistics for the study population

\begin{tabular}{|c|c|}
\hline Variable & Statistics \\
\hline \multicolumn{2}{|l|}{ Continuous variable } \\
\hline Age $(n=1855)$, median (LQ-UQ), y & $18(4-46)$ \\
\hline \multicolumn{2}{|l|}{ Time interval, mean $\pm \mathrm{SD}$, min } \\
\hline Response $(n=1798)$ & $8 \pm 5$ \\
\hline On-scene $(n=1525)$ & $19 \pm 17$ \\
\hline Transport $(n=1278)$ & $15 \pm 10$ \\
\hline \multicolumn{2}{|l|}{ Categorical variable, n (\%) } \\
\hline Age & 1855 \\
\hline Pediatric $^{a}$ & $919(50)$ \\
\hline Adult & $936(50)$ \\
\hline Sex & 1845 \\
\hline Male & $1200(65)$ \\
\hline Female & $645(35)$ \\
\hline Race & 1774 \\
\hline White & $1231(69)$ \\
\hline African American & $310(18)$ \\
\hline Latino & $95(5)$ \\
\hline Other & $138(8)$ \\
\hline Level of service & 1114 \\
\hline Basic life support & $240(22)$ \\
\hline Advanced life support & $874(79)$ \\
\hline Transport decision & 1859 \\
\hline Transported & $1248(67)$ \\
\hline Not transported & $611(33)$ \\
\hline Transport urgency & 1248 \\
\hline Emergent ${ }^{b}$ & $774(62)$ \\
\hline Nonemergent & $474(38)$ \\
\hline Cardiac arrest & 1859 \\
\hline Cardiac arrest & $537(29)$ \\
\hline No cardiac arrest & $1322(71)$ \\
\hline $\operatorname{ROSC}^{c}$ & $196(37)$ \\
\hline No ROSC & $341(64)$ \\
\hline
\end{tabular}

LQ, lower quartile; ROSC, return of spontaneous circulation; UQ, upper quartile.

${ }^{\mathrm{a}}$ Defined as age less than $18 \mathrm{y}$.

${ }^{\mathrm{b}}$ Of those transported.

${ }^{\mathrm{c}}$ Of those with cardiac arrest.

emergency traffic with activated lights and sirens, with the remaining encounters transported as routine traffic without lights and sirens.

Cardiac arrest was reported in 29\% $(\mathrm{n}=537,95 \%$ CI 27-31) of encounters. ROSC was reported in $37 \%$ $(\mathrm{n}=196,95 \%$ CI 32-41) of those presenting in cardiac arrest. A logistic regression model was performed for cardiac arrest and ROSC occurrence that accounted for age, sex, and race (Table 5). Cardiac arrest was reported less often for pediatric patients $(\mathrm{OR}=0.7,95 \% \mathrm{CI}$ 0.6-0.8) than adult patients. ROSC was reported more often in pediatric patients $(\mathrm{OR}=1.6,95 \%$ CI $1.1-2.3)$. This study showed a total prehospital fatality rate of $18 \%$ $(\mathrm{n}=341,95 \%$ CI 17-20).

\section{Discussion}

This study analyzed 1859 prehospital drowning encounters in the nationwide ESO database to determine population effects on prehospital time intervals and cardiac arrest frequency. Cardiac arrest occurrence was notably high; however, rates of successful cardiopulmonary resuscitation after drownings were higher than in general prehospital cardiac arrest encounters. ${ }^{9,10}$ Although adult patients presented with cardiac arrest more frequently, pediatric patients had higher rates of ROSC. Time intervals were found to be shorter in both pediatric and African American patients.

This study demonstrated a ROSC rate of $37 \%$ (95\% CI 32-41) for drowning patients. This is notably higher than the 11\% (95\% CIDP 24-28) and 10\% (95\% CIDP 24-28) prehospital ROSC rates after nondrowning cardiac arrest of unspecified origin. ${ }^{9,10}$ A study also examining survival rates after cardiac arrest due to drowning showed a similar ROSC rate of 34\% (95\% CIDP -0.02 to 0.07). ${ }^{11}$ Adults were found to present with cardiac arrest more frequently than their pediatric counterparts. This is most likely due to a higher prevalence of substance involvement and pre-existing conditions. In contrast, pediatric patients were found to have higher ROSC rates, possibly due to limited pre-existing conditions and closer attention by bystanders. Further studies examining these factors are warranted. It is important to note that although ROSC was more common in pediatric patients, both groups still demonstrated higher rates of ROSC than traditional cardiac arrest patients. In-hospital complications after ROSC in drowning patients increase mortality in the drowning population. This suggests that the longterm survivability of the patient population was lower than reported in this prehospital-focused study. These complications include aspiration pneumonia and poor neurologic outcome resulting from hypoxic brain injury. ${ }^{12,13}$ Another study suggested that only $8 \%$ of drowning patients who experience ROSC in the prehospital setting survive to hospital discharge. ${ }^{14}$ Although long-term survival could not be determined with these data, similar drowning studies suggest that worse outcomes were associated with male sex and the presence of specific chronic conditions. ${ }^{15,16}$

This study is consistent with the results of demographic disparities addressed in several other observational studies. White patients constituted the majority of drowning encounters in multiple studies. ${ }^{17-19}$ Males have been shown to have a higher frequency of drownings. ${ }^{18,20-22}$ Differences in sex have been attributed to increased time spent in water-related activities and risk-taking behaviors among males. ${ }^{18,19}$ The effects of race remain unclear. ${ }^{18,19}$ This study 
Table 3. Binomial proportion tests for categorical variables

\begin{tabular}{|c|c|c|c|}
\hline Variable & Male \% $(95 \% \mathrm{CI})$ & Female \% $(95 \%$ CI $)$ & Total \% $(95 \%$ CI $)$ \\
\hline \multicolumn{4}{|l|}{ Age } \\
\hline Pediatric $^{a}$ & $47(44-50)$ & $54(50-58)$ & $50(47-52)$ \\
\hline Adult & $53(50-56)$ & $46(42-50)$ & $50(48-53)$ \\
\hline \multicolumn{4}{|l|}{ Race } \\
\hline White & $69(66-71)$ & $71(68-75)$ & $69(67-72)$ \\
\hline African American & $18(16-20)$ & $15(13-19)$ & $18(16-19)$ \\
\hline Latino & $5(4-7)$ & $6(4-8)$ & $5(4-6)$ \\
\hline Other & $8(6-9)$ & $8(6-10)$ & $8(7-9)$ \\
\hline \multicolumn{4}{|l|}{ Level of service } \\
\hline Basic life support & $20(17-23)$ & $24(20-29)$ & $22(19-24)$ \\
\hline Advanced life support & $80(77-83)$ & $76(71-80)$ & $78(76-81)$ \\
\hline \multicolumn{4}{|l|}{ Transport decision } \\
\hline Transported & $67(64-70)$ & $68(64-72)$ & $67(65-69)$ \\
\hline Not transported & $33(30-36)$ & $32(28-36)$ & $33(31-35)$ \\
\hline \multicolumn{4}{|l|}{ Transport urgency } \\
\hline Emergent ${ }^{b}$ & $65(61-68)$ & $58(53-62)$ & $62(59-65)$ \\
\hline Nonemergent & $35(32-39)$ & $42(38-47)$ & $38(35-41)$ \\
\hline \multicolumn{4}{|l|}{ Cardiac arrest } \\
\hline Cardiac arrest & $31(28-34)$ & $25(22-29)$ & $29(27-31)$ \\
\hline No cardiac arrest & $69(66-72)$ & $75(71-78)$ & $71(69-73)$ \\
\hline $\operatorname{ROSC}^{c}$ & $35(30-40)$ & $40(33-48)$ & $37(32-41)$ \\
\hline No ROSC & $65(60-70)$ & $60(52-67)$ & $63(59-68)$ \\
\hline
\end{tabular}

$\mathrm{CI}$, confidence interval; ROSC, return of spontaneous circulation.

${ }^{\mathrm{a}}$ Defined as age less than $18 \mathrm{y}$.

${ }^{\mathrm{b}}$ Of those transported.

${ }^{c}$ Of those with cardiac arrest.

demonstrated a frequency of drownings that was slightly higher in the adult population $(51 \%)$. However, according to the United States Census Bureau, pediatric patients represent $22 \%$ of the United States population, suggesting a greater impact of drownings on the pediatric population. Regardless, deaths from drowning occur at younger ages relative to many other causes of death, resulting in a substantial loss of productive life years. ${ }^{17}$ Further research should attempt to address the cause of these disparities.

This study examined EMS time interval data for drowning patients. The average response time was $8 \pm 5$ min. This is consistent with the overall EMS mean response time of $8 \mathrm{~min},{ }^{23}$ suggesting no notable differences caused by drowning etiology. Response time was shorter for African American and pediatric patients, suggesting an inherent urgency with pediatric patients. Although the reasons for a faster response with African American patients are unclear, this could be because African American populations tend to concentrate around urban centers, which have higher concentrations of EMS bases and proximity to hospitals. ${ }^{24,25}$ On-scene time was $19 \pm 17 \mathrm{~min}$, longer than the target $10 \mathrm{~min}$ on-scene time adopted by most EMS systems. This reflects a possibly prolonged extrication requirement and on-scene resuscitation attempt. On-scene times were shorter for younger patients and longer for cardiac arrest patients. This is most likely due to the generally preferred expedited transport of pediatric patients by most prehospital providers and attempts to regain spontaneous circulation in cardiac arrest patients before transport. Comparison with transport time is difficult due to variance in scene location and destination distance. Times were shorter for African American patients owing to the increased concentration of hospitals in urban populations, and for cardiac arrest patients owing to their critical nature. This study showed an EMS transport frequency of $67 \%$, which was comparable to the overall national transport average of $71 \%$ (95\% CIDP -0.06 to -0.02$),{ }^{23}$ suggesting that drowning patients are similarly transported. Research with outcomes data should be completed to determine the clinical effect of these time discrepancies.

\section{LIMITATIONS}

This cross-sectional study retrospectively analyzed a single electronic medical record provider database of patients from EMS systems that have agreed to share their de-identified data for the purposes of research and benchmarking. These data are also observational. 
Table 4. General linear model for emergency medical services times

\begin{tabular}{lccc}
\hline Predictor & $\begin{array}{l}\text { Response } \\
\beta(95 \% \text { CI })\end{array}$ & $\begin{array}{l}\text { On-scene } \\
\beta(95 \% \text { CI })\end{array}$ & $\begin{array}{c}\text { Transport } \\
\beta(95 \% \text { CI })\end{array}$ \\
\hline $\begin{array}{l}\text { Pediatric } \\
\text { Cardiac arrest }\end{array}$ & $-1.5(-2.0$ to -1.1$)$ & $-9.1(-10.4$ to -7.9$)$ & $0.2(-0.9$ to 1.4$)$ \\
Sex & $-0.2(-0.7$ to 0.3$)$ & $3.4(2.1-4.8)$ & $-3.4(-4.7$ to -2.2$)$ \\
$\quad$ Female & ref & ref & ref \\
$\quad$ Male & $0.2(-0.4$ to 0.7$)$ & $0.6(-0.7$ to 1.9$)$ & $0.4(-0.8$ to 1.6$)$ \\
Race & & ref & ref \\
$\quad$ White & ref & $-1.3(-2.9$ to 0.3$)$ & $-2.6(-4.0$ to -1.2$)$ \\
$\quad$ African American & $-1.1(-1.7$ to -0.5$)$ & $-1.3(-4.2$ to 1.6$)$ & $-1.0(-3.6$ to 1.6$)$ \\
$\quad$ Hispanic or Latino & $-0.5(-1.5$ to 0.5$)$ & $1.1(-1.3$ to 3.5$)$ & $0.6(-1.6$ to 2.8$)$ \\
$\quad$ Other & $0.7(-0.2$ to 1.5$)$ &
\end{tabular}

CI, confidence interval; ref, reference category of comparison for other categories.

${ }^{a}$ Defined as age less than $18 \mathrm{y}$.

Therefore, inferences of causality are limited. This convenience sample is composed of a large number of encounters from the southern United States. Therefore, our results may not be generalizable to drowning patients in all EMS systems. Although demographics and cardiac arrest occurrences were significant, their clinical significance is unclear. Characteristic of retrospective prehospital research, the EMS dataset was limited and could not be linked with outcomes data and did not include any prehospital interventions. This study only addresses ROSC in the prehospital setting and does not provide any indication of improved resuscitation with neurologic recovery. Specific EMS agencies included were unknown, as were the urbanicity or rurality of where the encounters occurred. The definition of drowning is also historically challenging, with the possibility of documentation of

Table 5. Logistic regression model for cardiac arrest and return of spontaneous circulation occurrence

\begin{tabular}{lcc}
\hline Predictor & $\begin{array}{l}\text { Cardiac arrest odds } \\
\text { ratio }(95 \% \text { CI })\end{array}$ & $\begin{array}{l}\text { ROSC }^{a} \text { odds ratio } \\
(95 \% \text { CI })\end{array}$ \\
\hline $\begin{array}{l}\text { Pediatric } \\
\text { Sex } \\
\text { Female } \\
\text { Male }\end{array}$ & $0.7(0.6-0.8)$ & $1.6(1.1-2.3)$ \\
Race & ref & ref \\
White & $1.2(0.9-1.5)$ & $0.8(0.5-1.2)$ \\
$\begin{array}{l}\text { African } \\
\text { American } \\
\text { Hispanic or }\end{array}$ & ref & ref \\
Latino & $1.1(0.8-1.4)$ & $1.3(0.8-2.1)$ \\
Other & $1.0(0.4-1.1)$ & $0.9(0.3-2.3)$ \\
\hline
\end{tabular}

CI, confidence interval; ROSC, return of spontaneous circulation; ref, reference category of comparison for other categories.

${ }^{\mathrm{a}}$ Of those encounters presenting with cardiac arrest.

${ }^{\mathrm{b}}$ Defined as age less than $18 \mathrm{y}$. "drowning" events varying from region to region or provider to provider. This could lead to the inclusion or exclusion of misreported encounters in the dataset. With these limitations, drawing definitive conclusions regarding out-of-hospital time and mortality is impossible. Because of the current process of prehospital data collection and relative outliers, a substantial number of patients were excluded from certain calculations, which could lead to unintended selection bias. Manual data input or bias of prehospital providers could lead to unintended data collection errors.

\section{Conclusions}

This national prehospital drowning study demonstrates that despite an $18 \%$ fatality rate in drowning encounters, patients were more likely to have ROSC when compared to the overall prehospital national average, with rates higher in pediatric patients. Response times were shorter for pediatric and African American patients. On-scene times were shorter for pediatric patients and longer for cardiac arrest patients. Transport times were shorter for cardiac arrest and African American patients. Future studies with outcomes data should focus on identifying factors that improve cardiopulmonary resuscitation success rates.

Acknowledgments: We thank ESO, Dr. Nella Hendley, Dr. Remle Crowe, and Dr. Scott Bourn for their assistance in data acquisition.

Author Contributions: Study concept and design (LMP, NPA); acquisition of the data (JPS, HDM); analysis of the data (LMP, JPS); drafting of the manuscript (LMP); critical revision of the manuscript (NPA, HDM, JPS); approval of final manuscript (LMP, NPA, HDM, JPS).

Financial/Material Support: None.

Disclosures: None. 


\section{References}

1. Borse N, Gilchrist J, Dellinger AM, Rudd RA, Ballesteros MF, Sleet DA. CDC childhood injury report: patterns of unintentional injuries among 0-19 year olds in the United States, 2000-2006. CDC Childhood Injury Report. 2008;1:30.

2. Schmidt AC, Sempsrott JR, Hawkins SC, Arastu AS, Cushing TA, Auerbach PS. Wilderness Medical Society clinical practice guidelines for the treatment and prevention of drowning: 2019 Update. Wilderness Environ Med. 2016;27(2):236-51.

3. van Beeck EF, Branche CM, Szpilman D, Modell JH, Bierens JJLM. A new definition of drowning: towards documentation and prevention of a global public health problems. Bull World Health Organ. 2005;83(11):853-6.

4. Szpilman D, Bierens JJLM, Handley AJ, Orlowski JP. Drowning. N Engl J Med. 2012;366(22):2102-10.

5. Orlowski JP, Abulleil MM, Phillips JM. The hemodynamic and cardiovascular effects of near-drowning in hypotonic, isotonic, or hypertonic solutions. Ann Emerg Med. 1989;18(10):1044-9.

6. Grmec S, Strnad M, Podgorsek D. Comparison of the characteristics and outcome among patients suffering from out-of-hospital primary cardiac arrest and drowning victims in cardiac arrest. Int J Emerg Med. 2009;2(1):7-12.

7. Tipton MJ, Golden FS. A proposed decision-making guide for the search, rescue and resuscitation of submersion (head under) victims based on expert opinion. Resuscitation. 2011;82(7):819-24.

8. von Elm E, Altman DG, Egger M, Pocock SJ, Gotzsche PC, Vandenbroucke JP. The strengthening the reporting of observational studies in epidemiology statement: guidelines for reporting observational studies. Int $J$ Surg. 2014;12(12):1495-9.

9. Mozaffarian D, Benjamin EJ, Go AS, Arnett DK, Blaha MJ, Cushman M, et al. Heart disease and stroke statistics-2015 update. Circulation. 2015;131(4):e29-322.

10. Daya MR, Schmicker RH, May S, Morrison L. Current burden of cardiac arrest in the United States: report from the resuscitation outcomes consortium. Inst. Med. 2015;7.

11. Claesson A, Lindqvist J, Herlitz J. Cardiac arrest due to drowning - changes over time and factors of importance for survival. Resuscitation. 2014;85(5):644-8.

12. Cerland L, Megarbane B, Kallel H, Brouste Y, Mehdaoui H, Resiere D. Incidence and consequences of near-drowning-related pneumonia-a descriptive series from Martinique, French West Indies. Int J Environ Res Public Health. 2017;14(11):1402.

13. Suominen PK, Vahatalo R. Neurologic long term outcome after drowning in children. Scand J Trauma Resusc Emerg Med. 2012;20:55.

14. Dyson K, Morgans A, Bray J, Matthews B, Smith K. Drowning related out-of-hospital cardiac arrests: characteristics and outcomes. Resuscitation. 2013;84(8):1114-8.

15. Dakessian A, Bachir R, El Sayed M. Impact of trauma designation levels on survival of drowning victims: an observational study from trauma centers in the United States. Medicine (Baltimore). 2019;98(43), e17721.

16. El Sibai R, Bachir R, El Sayed M. Submersion injuries in the United States: patient characteristics and predictors of mortality and morbidity. Injury. 2018;49(3):543-8.

17. Browne ML, Lewis-Michl EL, Stark AD. Unintentional drownings among New York state residents, 1988-1994. Public Health Rep. 2003;118(5):448-58.

18. Patetta MJ, Biddinger PW. Characteristics of drowning deaths in North Carolina. Public Health Rep. 1988;103(4):406-11.

19. Quan L, Cummings P. Characteristics of drowning by different age groups. Inj Prev. 2003;9(2):163-8.

20. O'Carroll PW, Alkon E, Weiss B. Drowning mortality in Los Angeles County, 1976 to 1984. JAMA. 1988;260(3):380-3.

21. Hedberg K, Gunderson PD, Vargas C, Osterholm MT, MacDonald KL. Drownings in Minnesota, 1980-85: a population-based study. Am J Public Health. 1990;80(9):1071-4.

22. Dietz PE, Baker SP. Drowning: epidemiology and prevention. Am J Public Health. 1974;64(4):303-12.

23. Mell HK, Mumma SN, Hiestand B, Carr BG, Holland T, Stopyra J. Emergency medical services response times in rural, suburban, and urban areas. JAMA Surg. 2017;152(10):983-4.

24. Parker K, Horowitz J, Brown A, Fry R, Cohn D, Igielnik R. What unites and divides urban, suburban and rural communities. Pew Research Center Rep. 2018;1.

25. Ashburn NP, Hendley NW, Angi RM, Starnes AB, Nelson RD, McGinnis HD, et al. Prehospital trauma scene and transport times for pediatric and adult patients. West $J$ Emerg Med. 2020;21(2):455-62. 